\title{
Energy Drink Consumption among College Students in Saudi Arabia
}

\author{
Abdullah A. Katib ${ }^{1, *}$, Hani Almalki ${ }^{2}$, Amal Surrati ${ }^{3}$, Zeidan A. Zeidan ${ }^{3}$ \\ ${ }^{1}$ Public Health Administration, Ministry of Health, Madinah, Saudi Arabia \\ ${ }^{2}$ Public Health Administration, Ministry of Health, Makkah, Saudi Arabia \\ ${ }^{3}$ Department of Family and Community Medicine, Taibah University, Madinah, Saudi Arabia \\ *Corresponding author:dr.abduk@hotmail.com
}

Received June 29, 2018; Revised August 08, 2018; Accepted September 06, 2018

\begin{abstract}
The increased consumption of energy drinks by adolescents and young adults globally is a public concern due to the high amount of caffeine and sugar in them, which may affect consumers' health. Only one study was found in Madinah that measure the prevalence of energy drink consumption, but it was conducted with female students of secondary school. The prevalence of energy drink consumption is high and there is evidence of affecting health of the population. The objective of this study was to determine the patterns of consumption of energy drinks among college students in Madinah, Saudi Arabia. The study was conducted at Taibah university in Madinah. The sample included 380 students of the main branch of Taibah university in Madinah, which contains 29153 students. Data were collected using a self-administered questionnaire consisting of 20 questions relating to students' sociodemographic characteristics, personal habits, total fluid intake, energy drink-related knowledge, and habits. Of the 380 students surveyed, 127 (33.4\%) student were regularly consuming energy drinks. The mean age and standard deviation were $21.24 \pm 1.77$. Pearson chi-square test was done and it showed statistically significant association between energy drinks and smoking (13.522) with P value 0.0002. A majority of surveyed students had good knowledge regarding energy drinks. Future studies are needed to determine harmful side effects of energy drinks.
\end{abstract}

Keywords: energy drinks, college student, intake, survey

Cite This Article: Abdullah A. Katib, Hani Almalki, Amal Surrati, and Zeidan A. Zeidan, "Energy Drink Consumption among College Students in Saudi Arabia." Journal of Food and Nutrition Research, vol. 6, no. 8 (2018): 531-536. doi: 10.12691/jfnr-6-8-8.

\section{Introduction}

Energy drinks are global public concerns due to their increased consumption by adolescents and young adults because they contain high amount of caffeine and sugar that may affect the health of the population. Energy drinks have many types that differ in the composition of their active ingredients. The active ingredients found in energy drinks are: Caffeine, Taurine, Guarana, Ginseng, Yerba mate, B vitamins, Ginkgo Biloba, L-Carnitine, Glucuronolactone, Creatine, Acai Berry, Milk Thistle, and L-theanine. Energy drinks contain some bio-active constituents that may stimulate the brain and could lead to harmful consequences to the health of their consumers. [1] Hence, many researches have been carried out to study the side effects of energy drink consumption on human health. In Saudi Arabia, the Saudi Council of Ministers has decided to restrict the advertisement of energy drinks as well as distribution of free energy drinks to consumers of all age groups because of a recent significant rise in sudden cardiac deaths among healthy young individuals. This restriction also prohibits the sale of energy drinks in restaurants, government facilities, health and education facilities, halls of government, and private sports clubs. Additionally, on June 11, 2017, Saudi Arabia started implementing excise tax on goods having adverse impact on public health or environment or on luxury goods in varying proportions including energy drinks, which was $100 \%$ tax. [2] However, the prevalence of energy drink consumption in Saudi Arabia is high with slight regional differences. In Madinah, a study was conducted in 2011 to find the prevalence of energy drink consumption in female students of secondary schools and it found that $52.2 \%$ of the study population consumed energy drinks. [3] In Jeddah, a study conducted in 2013 regarding the knowledge, attitudes, and practices pertaining to energy drinks among adolescents found that $45 \%$ of the study population consumed energy drinks. [4] In Makkah, in a study conducted in 2016 to determine the prevalence of energy drink consumption among adolescents and young adults, the researchers found that $46.73 \%$ of the study population consumed energy drinks. [5] A study in Riyadh in 2016 found that the consumption of energy drinks was 71.6\% among college students. [6] A study aiming to describe the benefits and side effects of energy drink consumption found that there were no therapeutic benefit 
or side effects because the dose of guarana, taurine, and ginseng that were found in popular energy drinks are far below the amounts expected to cause any effect. On the other hand, the study found that the concentration of caffeine and sugar in the energy drinks are high and can cause serious side effects. [7] Therefore, the objective of this study was to access the patterns of consumption of energy drinks among college students in Madinah, Saudi Arabia.

\section{Materials and Methods}

The Institutional Review Board of Taibah University approved this study and questionnaire. The survey method was discussed with the participants who were both male and female college students from Madinah, Saudi Arabia. Questionnaires were employed to measure students' use of and perceptions about energy drinks. The results were compared and analyzed to find the extent and level of consumption of energy drinks by the study participants. A consent form was presented along with the survey containing a description of the research and the nature of the survey.

\subsection{Study Setting and Population}

The study was conducted at the main branch of Taibah university with male and female students in Madinah. It is the main university in Madinah, containing 29153 students, of which 10414 students are male and 18739 students are female. [8] It contains 28 colleges, of which 16 are in the main branch in Madinah. [9]

\subsection{Sampling Method}

Three hundred eighty male and female college students were recruited as participants using stratified and systematic sampling technique. First, we divided the university by college specialty into 14 colleges and then randomly recruited a representative sample from each college. When a chosen student was not available or refused to participate, another was recruited randomly from the same college. Each gender group was assigned a coordinator who had the role of organizing recruitment efforts.

\subsection{Survey Questionnaire}

We used an interview questionnaire with questions on sociodemographic factors, causes, patterns of use of energy drinks, knowledge of their components and possible side-effects, and preferred types of energy drinks. The questionnaire was adopted from a similar previous study conducted among college students in Riyadh, Saudi Arabia, [6] but it was modified to include demographic factors; doctor's diagnosis of diabetes mellitus, hypertension, or renal disorders; and any regular use of medications. The questionnaire was translated into Arabic using forward and back translation to ensure that the translation did not change the contents and meaning of the questionnaire. The Arabic version was used as most participants did not speak English.

\subsection{Data Collection}

The survey administration and data collection occurred from January-March 2018 using a self-administered questionnaire.

\subsection{Statistical Analysis}

The data were analyzed using SPSS version 20. Variables analyzed were the student attitudes measured with the questionnaire consisting of 20 questions divided into five different categories including sociodemographic factors, smoking and the use of energy drinks, reason for consumption, personal beliefs, and behavior and other variables. Results were analyzed using chi-square tests with a significance level of 0.05 .

\section{Results}

This study focused on the consumption of and attitudes towards energy drinks among college students in Madinah, Saudi Arabia. Table 1 shows the sociodemographic features of college students who participated in the survey. Of the total of 380 participants in the survey, 37.9\% $(n=$ $144)$ were male and $62.1 \%(n=236)$ were female; $97.4 \%$ ( $\mathrm{n}=370)$ were Saudi and $2.6 \%(\mathrm{n}=10)$ were Non-Saudi; and $93.4 \%(n=355)$ were single and $6.6 \%(n=25)$ were married. Study participants consisted of male and female college students with ages ranging from 19 to 30 years (mean and standard deviation were $21.08 \pm 1.68$ ).

Table 1. Socio-demographic features of college students that participated in the survey

\begin{tabular}{lcc}
\hline Sociodemographic features & P & \% \\
\hline Age (years) & 253 & \\
$18-21$ & 121 & 66.6 \\
$22-25$ & 6 & 31.8 \\
$26-30$ & 380 & 1.6 \\
Total & & 100 \\
Gender & 144 & \\
Male & 236 & 37.9 \\
Female & 380 & 62.1 \\
Total & & 100 \\
Nationality & 370 & \\
Saudi & 10 & 97.4 \\
Non-Saudi & 380 & 2.6 \\
Total & & 100 \\
Marital status & 355 & \\
Single & 25 & 93.4 \\
Married & 380 & 6.6 \\
Total & & 100 \\
\hline
\end{tabular}

Table 2 shows survey questions regarding smoking and the reasons for using energy drinks. In the first question, we asked if the students were smokers. Of the 380 students surveyed, $13.7 \%(n=52)$ were currently smoking and $86.3 \%(n=328)$ were non-smokers. The second question was about consuming energy drinks. Of the 380 students surveyed, 127 were using energy drinks (mean age and standard deviation were $21.24 \pm 1.77$ ). Thus, we decided to focus only on those 127 (33.4\%) participants 
who actually use energy drinks. Table 3 shows the exact percentage of smoking and energy drink consumption in relation to gender. It shows that $29.9 \%(n=43)$ of surveyed male students were smokers while only $3.9 \%(n=9)$ of female students were smokers. Moreover, 38.9\% $(n=56)$ of surveyed male students were using energy drinks while $30.1 \%(n=71)$ of female students were doing so.

In the question relating to the number of cans of energy drinks used per week, the results showed that a majority of students ( $n=71 ; 55.9 \%)$ used only one can of energy drink, and $22 \%(n=28)$ students used two cans per week. Additionally, $10.2 \%$ of students reported using three cans ( $n=13$ ), which was the same as those using five or more cans $(n=13 ; 10.2 \%)$, while a minority of students used four cans $(n=2 ; 1.6 \%)$ per week.

In the question relating to the main reason for using energy drinks, results showed that students consumed energy drinks for different reasons. The survey showed that most students $(58.3 \%, \mathrm{n}=74)$ were consuming energy drinks for other reasons than those mentioned in the survey, whereas $22.8 \%(n=29)$ of students were consuming energy drinks to study for exams or finish a project. In addition, $17.3 \%(n=22)$ reported that getting energy (speed, strength, and power) was their reason for consuming energy drinks. Fewer than 2\% of students indicated consuming energy drinks to enhance academic performance or help recover from injury or illness. Most students ( $n=39 ; 30.7 \%)$ reported sources other than those mentioned in the questionnaire as their main source of information on energy drinks, followed by retail stores ( $n=36 ; 28.3 \%$ ), and family members or friends $(n=34$; $26.8 \%$ ). Fewer than $15 \%$ students reported their sources of information as being the internet, coach or physician, and nutritionist or dietician resources.

Table 2. Smoking and use of energy drinks among college students $(\mathbf{n}=380)$

\begin{tabular}{|c|c|c|}
\hline Response & $\mathbf{N}$ & $\%$ \\
\hline \multicolumn{3}{|l|}{ Do you currently smoke? } \\
\hline Yes & 52 & 13.7 \\
\hline No & 328 & 86.3 \\
\hline \multicolumn{3}{|l|}{ Do you currently take an energy drink? } \\
\hline Yes & 127 & 33.4 \\
\hline No & 253 & 66.6 \\
\hline \multicolumn{3}{|c|}{ How many cans of energy drinks do you drink per week? } \\
\hline More than 5 & 13 & 10.2 \\
\hline 4 & 2 & 1.6 \\
\hline 3 & 13 & 10.2 \\
\hline 2 & 28 & 22 \\
\hline 1 & 71 & 55.9 \\
\hline \multicolumn{3}{|c|}{ What is your main reason for using energy drinks? } \\
\hline Studying for exams or finishing a project & 29 & 22.8 \\
\hline Enhancing academic performance & 2 & 1.6 \\
\hline Helping to recover from an injury or illness & 0 & 0.0 \\
\hline Getting energy (speed, strength, and power) & 22 & 17.3 \\
\hline Other & 74 & 58.3 \\
\hline \multicolumn{3}{|c|}{ From where you get information about energy drinks? } \\
\hline Coach or physician & 3 & 2.4 \\
\hline Nutritionist or dietician & 2 & 1.6 \\
\hline Family or friends & 34 & 26.8 \\
\hline Internet & 13 & 10.2 \\
\hline Retail store & 36 & 28.3 \\
\hline Other & 39 & 30.7 \\
\hline
\end{tabular}

Table 3. Smoking and use of energy drinks among college students by gender $(n=380)$

\begin{tabular}{lcc}
\hline & \multicolumn{2}{c}{ Gender } \\
& Male & Female \\
\hline Smoking & & \\
Yes & $43(29.9 \%)$ & $9(3.8 \%)$ \\
No & $101(70.1 \%)$ & $227(96.2 \%)$ \\
Energy drink consumption & & \\
Yes & $56(38.9 \%)$ & $71(30.1 \%)$ \\
No & $88(61.1 \%)$ & $165(69.9 \%)$ \\
\hline
\end{tabular}

Table 4. Strength of association between energy drink usage and categorized variables

\begin{tabular}{lcc}
\hline Energy drink usage association & Pearson chi-square & P value \\
\hline Gender & 3.115 & 0.078 \\
Nationality & 0.831 & 0.362 \\
Marital status & 0.024 & 0.876 \\
Smoking & 13.522 & 0.0002 \\
\hline
\end{tabular}

Table 5. Perception about energy drinks and their consumption among college students $(n=127)$

\begin{tabular}{|c|c|c|}
\hline Response & $\mathbf{N}$ & $\%$ \\
\hline \multicolumn{3}{|c|}{ Energy drinks make me healthier. } \\
\hline Agree & 6 & 4.7 \\
\hline Somewhat agree & 14 & 11 \\
\hline Neither agree nor disagree & 20 & 15.7 \\
\hline Somewhat disagree & 18 & 14.2 \\
\hline Disagree & 65 & 51.2 \\
\hline Do not know & 4 & 3.1 \\
\hline \multicolumn{3}{|c|}{ Energy drinks improve my endurance. } \\
\hline Agree & 18 & 14.2 \\
\hline Somewhat agree & 31 & 24.4 \\
\hline Neither agree nor disagree & 14 & 11 \\
\hline Somewhat disagree & 13 & 10.2 \\
\hline Disagree & 47 & 37 \\
\hline Do not know & 4 & 3.1 \\
\hline \multicolumn{3}{|c|}{ Energy drinks are safe to use. } \\
\hline Agree & 5 & 3.9 \\
\hline Somewhat agree & 12 & 9.4 \\
\hline Neither agree nor disagree & 11 & 8.7 \\
\hline Somewhat disagree & 20 & 15.7 \\
\hline Disagree & 75 & 59.1 \\
\hline Do not know & 4 & 3.1 \\
\hline \multicolumn{3}{|c|}{ Energy drinks provide me with more energy. } \\
\hline Agree & 41 & 32.3 \\
\hline Somewhat agree & 32 & 25.2 \\
\hline Neither agree nor disagree & 12 & 9.4 \\
\hline Somewhat disagree & 10 & 7.9 \\
\hline Disagree & 30 & 23.6 \\
\hline Do not know & 2 & 1.6 \\
\hline \multicolumn{3}{|c|}{ Energy drinks increase the amount of training I can undergo. } \\
\hline Agree & 20 & 15.7 \\
\hline Somewhat agree & 20 & 15.7 \\
\hline Neither agree nor disagree & 21 & 16.5 \\
\hline Somewhat disagree & 12 & 9.4 \\
\hline Disagree & 42 & 33.1 \\
\hline Do not know & 12 & 9.4 \\
\hline \multicolumn{3}{|c|}{ Energy drinks increase my strength. } \\
\hline Agree & 20 & 15.7 \\
\hline Somewhat agree & 25 & 19.7 \\
\hline Neither agree nor disagree & 20 & 15.7 \\
\hline Somewhat disagree & 13 & 10.2 \\
\hline Disagree & 46 & 36.2 \\
\hline Do not know & 3 & 2.4 \\
\hline \multicolumn{3}{|c|}{ Energy drinks increase my ability to tolerate pain. } \\
\hline Agree & 12 & 9.4 \\
\hline Somewhat agree & 10 & 7.9 \\
\hline Neither agree nor disagree & 13 & 10.2 \\
\hline Somewhat disagree & 14 & 11 \\
\hline Disagree & 70 & 55.1 \\
\hline Do not know & 8 & 6.3 \\
\hline \multicolumn{3}{|c|}{ Energy drinks improve my concentration. } \\
\hline Agree & 27 & 21.3 \\
\hline Somewhat agree & 33 & 26 \\
\hline Neither agree nor disagree & 14 & 11 \\
\hline Somewhat disagree & 9 & 7.1 \\
\hline Disagree & 39 & 30.7 \\
\hline Do not know & 5 & 3.9 \\
\hline
\end{tabular}


Table 4 shows the association between energy drink consumption and gender, marital status, and smoking derived using Pearson chi-square test with a significance level of $<0.05$. We reported that there was a statistically significant association between energy drink consumption and smoking with Pearson chi-square value of 13.522 with significance level of $<0.001$, whereas it showed a statistically insignificant association with gender, nationality, and marital status, with values of $0.078,0.362$, and 0.876 respectively.

Table 5 shows responses to questions about the perceptions about energy drinks among college students in Madinah, Saudi Arabia. Questions 13 to 20 in the study dealt with the students' perceptions about the use of energy drinks. A majority of college students (51.2\%; $n=65$ ) thought that energy drinks were not a healthy choice and 37\% $(n=47)$ believed that energy drinks could not improve endurance. Most students surveyed (59.1\%; $n=75$ ) thought that the energy drinks were not safe and 32.3\% $(n=41)$ believed that energy drinks are a good source of energy. Forty two (33.1\%) students reported that energy drinks did not support longer training sessions and $36.2 \%(n=46)$ felt that energy drinks did not help to increase strength. A majority of students $(55.1 \% ; n=70)$ disagreed that energy drinks relieved pain during training sessions and 39 students (30.7\%) disagreed with the use of energy drinks to enhance concentration.

In our study, we were also interested in knowing the types of energy drinks that were consumed by these college students. Table 6 shows the list of energy drinks that college students reported using and it included more than seven products. Our results showed that Code Red ( $n=52 ; 40 \%$ ) and Mixed types ( $n=42 ; 33.1 \%$ ) were the most popular energy drinks used by the students, followed by other types than those mentioned in the questionnaire ( $n=14 ; 11 \%)$, Bison ( $n=7 ; 5.5 \%)$, Red Bull $(n=5$; $3.9 \%)$, Power Horse $(n=4 ; 3.1 \%)$, and Double Horse $(n=2 ; 1.6 \%)$.

Table 6. Type of energy drinks consumed among college students (n = 127)

\begin{tabular}{lcc}
\hline Category of Energy Drink & N & \% \\
\hline $\begin{array}{l}\text { Which of these energy drinks have you used } \\
\text { most frequently? }\end{array}$ & & \\
Red Bull & 5 & 3.9 \\
Code Red & 52 & 40 \\
Bison & 7 & 5.5 \\
Bugzy & 1 & 0.8 \\
Power Horse & 4 & 3.1 \\
Double Horse & 2 & 1.6 \\
Mixed & 42 & 33.1 \\
Other & 14 & 11 \\
\hline
\end{tabular}

\section{Discussion}

In this study, we conducted a survey about the usage of energy drinks by college students $(n=380)$ at Taibah University in Madinah. Based on our results, college students generally appeared to have a good knowledge about energy drink ingredients or the potential side effects of using these popular drinks.

In contrast to other studies on the use of energy drinks conducted in Saudi Arabia, our study found that of 380 college students surveyed, only 127 (33.4\%) were currently consuming energy drinks. Meanwhile, other studies found that the prevalence of energy drinks consumption were 52.2\% in Madinah 2011, [3] 45\% in Jeddah 2013, [4] 46.73\% in Makkah 2016, [5] and 71.6\% in Riyadh 2016. [6] Thus, it appears that the use of energy drinks in our study was the least among other studies that were conducted in Saudi Arabia, possibly due to the recent excise tax of $100 \%$ on energy drinks among other products that was implemented in June 2017 [2] and increased awareness of the population about energy drinks.

We decided to compare the results of our study with those of the study about energy drink usage conducted in Riyadh in 2016 because it was the last study done in Saudi Arabia, and we adopted the questionnaire from it. [6] In our study, the results showed that the prevalence of energy drink usage was $33.4 \%$, while it was $71.6 \%$ in the other study. Additionally, the most frequent usage of energy drinks among students in our study was one can per week (55.9\%), similar to the other study, which reported 39.3\%. Regarding the primary reason for consuming energy drinks, our results showed that $41.7 \%$ students consumed energy drinks for a variety of reasons. For example, 22.8\% reported that completing a project or studying for exams was the reason for consuming energy drinks; $17.3 \%$ consumed energy drinks to get energy (speed, strength, and power), while only $1.6 \%$ reported that enhancing academic performance was their reason for consuming energy drinks.

Regarding the attitude and perception about energy drinks, our study showed that the surveyed students had better knowledge about energy drinks and its effects than the students surveyed in the other study. For example, $51.2 \%$ of students from our study thought that energy drinks do not make them healthier, while $54.4 \%$ of students from the compared study thought that energy drinks make them healthier. Moreover, 37\% students did not think that energy drinks improve their endurance while $64.5 \%$ of students from the compared study thought that energy drinks can improve their endurance. In addition, $59.1 \%$ thought that energy drinks are not safe to use, and $32.3 \%$ agreed that the drinks provide them with more energy; 33.1\% thought that the drinks do not increase the amount of training they can undergo, whereas $36.2 \%$ did not think that consuming energy drinks can increase their strength; $55.1 \%$ did not think that it can increase their ability to tolerate pain and $30.7 \%$ did not think that energy drinks can increase their concentration. While the compared study showed that $48.2 \%$ thought that energy drinks are safe to use; $66.7 \%$ agreed that the drinks provided them with more energy; 54.7\% thought that the drinks increased the amount of training they can undergo; $43.2 \%$ thought that the drinks can increase their strength; $38.8 \%$ believed that the drinks can increase their ability to tolerate pain; and $42 \%$ thought that energy drinks can increase their concentration.

Regarding energy drinks' side effects, many studies were done. For example, a study trial was conducted on normal albino rats to assess the biochemical effects of energy drinks alone or in combination with alcohol. Twenty male albino rats were assigned to five different groups by allocating four rats in each group. Two groups were given low and high doses of energy drinks alone, respectively, while the other two groups were given low and high doses of energy drinks in combination with 
alcohol, respectively; the last group was given distilled water and worked as the control group. After 30 days, the animals were killed and their blood collected for laboratory analysis. The results were significant regarding the effect of energy drinks alone or in combination with alcohol on total white blood cell count, plasma potassium, calcium, renal functions, liver enzymes, and plasma triglycerides with more effects of energy drinks combined with alcohol than energy drinks alone. [10]

Likewise, in a case report of acute kidney injury after daily consumption of Red Bull energy drink for two to three consecutive weeks, authors concluded that acute renal failure was not caused by energy drinks alone. They described a patient with signs and symptoms of subacute renal failure, which were resolved after stopping the consumption of Red Bull energy drink. Lack of knowledge of the last date of consumption of Red Bull in relation to renal function improvement limited this conclusion. Another limitation was laboratory error chances or contamination of the product. Moreover, some health conditions may have precipitated the renal failure, like history of diabetes mellitus type 2, recent viral illness, possible dehydration, and occasional use of ibuprofen but they were unlikely to have expedited this event. The patient had no past history of renal dysfunction. After discontinuing Red Bull consumption for two weeks, Serum Creatinine and laboratory markers returned to. [11]

A systematic review was done and published in 2014 and it retrieved the studies regarding energy drinks that were published between 1966 and February 2011 and included them if they met the criteria of being randomized or pseudo randomized control trials with; studied a human population; reported a health-related measure; and investigated a whole ED. At the end, 15 studies were identified. The following outcome measures were included: cardiorespiratory effects, physiological measures, pathological measures, and body composition. In this review, the mean energy drink dosage was 390mL (range: $250-750 \mathrm{~mL}$ ). From the studies that were involved in this review, commercial energy drinks' funding and/or study associations were identified in six studies. Studies investigating long-term consumption and follow-up were lacking. The findings from this review were not conclusive regarding dietary recommendations about safe levels of energy drink consumption. We need further high-quality studies to be sure about energy drinks' safety. [12]

A randomized crossover study was done to find the effect of energy drinks on cardio- and cerebrovascular systems. The researchers found that Red Bull consumption led to significant increases in both systolic and diastolic blood pressure. It was also associated with significant increases in heart rate and cardiac output. The total peripheral resistance did not significantly change and the endothelial response to acetylcholine was not affected. Additionally, Red Bull utilization caused a significant increase in both cerebrovascular resistance and breathing frequency. It was also associated with significant decreases in cerebral blood flow velocity and end-tidal carbon dioxide. [13]

A 2-period crossover pilot study was done to compare the effects of energy drinks and caffeine supplementation on blood pressure indices. The study was conducted with healthy, nonsmoking, normotensive volunteers aged 18-45 years and taking no medications. The measurements were done with 24-hour ambulatory blood pressure monitoring (ABPM). During each period, participants received either an energy drink or compounded caffeine solution four times daily and then they underwent the 24-hour ABPM. The study periods were separated by a washout period ranging from 4-30 days. The study concluded that a single-day energy drink supplementation significantly increases mean 24-hour and daytime blood pressure compared to caffeine control in this pilot study. In addition, the study recommended additional research. [14]

Another experimental study was performed with healthy young adults to determine the effects of energy drink consumption on blood pressure, heart rate, and electrocardiographic parameters. After ingestion of energy drinks, the result of the study was significant regarding heart rate decline and occurrence of more frequent ST-T changes. On the other hand, the result of the study was insignificant regarding readings for systolic and diastolic blood pressure, PR interval, QRS duration, and QT interval post-consumption. [15]

A study was conducted among children and adolescents to explore the effect of energy drink and caffeinated beverage consumption on their sleep, mood, and performance. The researchers found that most participants were consuming highly caffeinated drinks in order to bring down the effects of chronic sleep loss but this behavior may have significant adverse effects for general health, performance, and safety. Furthermore, the association between energy drink consumption and other inappropriate sleep behaviors such as later bedtimes and excessive use of electronics may increase the interest in the harmful effects of caffeine on sleep health. [16]

\section{Conclusion}

Many college students consume energy drinks as a part of their daily habits. Our study found that there had increased awareness about benefits and side effects of energy drinks as compared to samples in previous studies as well as decreased prevalence of their consumption apparently due to new excise tax of $100 \%$ on energy drinks that had been implemented recently. More researches are needed to increase awareness and deeper understanding of their effects. Future studies are needed and recommended to determine dangerous side effects of energy drinks.

\section{Acknowledgements}

We would like to thank the Saudi board of Community Medicine in Madinah for their help to complete this research. We would also thank the students who helped me by collecting the data, including Abdulaziz Ashraf Saeed, Israa Ismail Mohammed AlTurkestany, Fatima Daif Allah Soliman Alharbi, Rawan Ahmed M Alotaibi, and Nada Rasheed Abdullah Almshhen.

\section{List of Abbreviations}

ABPM: ambulatory blood pressure monitoring 


\section{References}

[1] Yunusa I, Ahmad I. Energy- Drinks: Composition and Health Benefits. Bayero J Pure Appl Sci. 2011; 4(2): 186-91.

[2] Excise Tax | General Authority OF ZAKAT \&amp; TAX [Internet]. [cited 2018 Jun 10]. Available from: https://www.gazt.gov.sa/en/laws-regulations/excise-tax.

[3] Aluqmany R, Mansoor R, Saad U, Abdullah R, Ahamd A. Consumption of energy drinks among female secondary school students, Almadinah Almunawwarah, Kingdom of Saudi Arabia, 2011. J Taibah Univ Med Sci [Internet]. 2013 Apr [cited 2017 Mar 4]; 8(1): 60-5.

[4] Musaiger A, Zagzoog N. Knowledge, attitudes and practices toward energy drinks among adolescents in Saudi Arabia. Glob J Health Sci [Internet]. Canadian Center of Science and Education; 2013 Nov 27 [cited 2017 Mar 4];6(2): 42-6.

[5] Elsoadaa SS, Hejazi HH, Sonbul AA, Fayyadhah SA, Al-Ahdal SE, Al-Turkistani SA, et al. Prevalence of Energy Drinks Consumption among Adolescents and Young Adults in Makkah, KSA. J Heal Med Nurs [Internet]. 2016 [cited 2017 Mar 4]; 33(0): 79-90.

[6] O. Aljaloud S. Use of Energy Drinks Among College Students in Saudi Arabia. Am J Sport Sci [Internet]. Science Publishing Group; 2016 [cited 2017 Mar 4]; 4(3): 49.

[7] Clauson KA, Shields KM, McQueen CE, Persad N, Jean F, Starkey C. Safety issues associated with commercially available energy drinks. Pharm TODAYssMAY [Internet]. 2008 [cited 2017 Jan 11];14(5):52-64.

[8] جامعة طيبة | البيانات المفتوحة [Internet]. [cited 2017 Apr 27]. Available from: https://www.taibahu.edu.sa/Pages/AR/CustomPage.aspx?ID=87.
[9] جامعة طيبة | عن الجامعة [Internet]. [cited 2017 Apr 27]. Available from:

https://www.taibahu.edu.sa/Pages/AR/CustomPage.aspx?ID=41

[10] Ugwuja E. Biochemical effects of energy drinks alone or in combination with alcohol in normal albino rats. Adv Pharm Bull [Internet]. 2014 [cited 2017 Feb 12];4(1): 69-74.

[11] Greene E, Oman K, Lefler M. Energy Drink-Induced Acute Kidney Injury. Ann Pharmacother [Internet]. 2014 Oct 1 [cited 2017 Jan 12]; 48(10): 1366-70.

[12] Burrows T, Pursey K, Neve M, Stanwell P. What are the health implications associated with the consumption of energy drinks? A systematic review. Nutr Rev [Internet]. 2013 Mar [cited 2017 Jan 12]; 71(3): 135-48.

[13] Grasser EK, Yepuri G, Dulloo AG, Montani J-P. Cardio- and cerebrovascular responses to the energy drink Red Bull in young adults: a randomized cross-over study. Eur J Nutr [Internet]. 2014 Oct 29 [cited 2017 Jan 12]; 53(7): 1561-71

[14] Franks AM, Schmidt JM, McCain KR, Fraer M. Comparison of the Effects of Energy Drink Versus Caffeine Supplementation on Indices of 24-Hour Ambulatory Blood Pressure. Ann Pharmacother [Internet]. 2012 Feb 1 [cited 2017 Jan 12]; 46(2): 192-9.

[15] Hajsadeghi S, Mohammadpour F, Manteghi MJ, Kordshakeri K, Tokazebani M, Rahmani E, et al. Effects of energy drinks on blood pressure, heart rate, and electrocardiographic parameters: An experimental study on healthy young adults. 2015 [cited 2017 Jan 11]; Available from: www.anatoljcardiol.com

[16] Owens JA, Mindell J, Baylor A. Effect of energy drink and caffeinated beverage consumption on sleep, mood, and performance in children and adolescents. Nutr Rev [Internet]. 2014 Oct [cited 2017 Jan 12]; 72 :65-71. 